ARTIGO DE REVISÃO

ISSN 1677-5090

(C) 2015 Revista de Ciências Médicas e Biológicas

\title{
Impacto do tratamento periodontal não-cirúrgico nos níveis plasmáticos da proteína C-Reativa em pacientes com periodontite crônica: revisão da literatura
}

\author{
High serum crp in patients with chronic periodontitis \\ José Alberto da Silva Franceschine ${ }^{1 *}$, Fernanda Brito², Carlos Marcelo Figueredo ${ }^{3}$ \\ ${ }^{1}$ Mestre. Centro de Ciências da Saúde. UVA; 2Professor Adjunto Doutor de Periodontia. UFF; Pesquisador. UVA; \\ ${ }^{3}$ Professor Adjunto Doutor de Periodontia, UERJ.
}

\begin{abstract}
Resumo
Introdução: Desde que foi demostrado que a periodontite é capaz de induzir o aumento dos níveis da proteína C-reativa (CRP), estudos têm buscado demonstrar o impacto do tratamento periodontal nos níveis da CRP, mas com resultados inconsistentes. Objetivo: desse artigo foi avaliar o impacto do tratamento periodontal nos níveis da CRP em indivíduos com periodontite crônica (PC). Metodologia: buscas foram realizadas em bases de dados nacionais e internacionais até fevereiro 2014. Os parâmetros avaliados foram: parâmetros periodontais (profundidade de sondagem, nível de inserção, índice de placa e sangramento à sondagem, quantidade de sítios avaliados por dente); tempo de reavaliação após o tratamento periodontal, fatores de exclusão e prescrição de antibióticos. Resultados: Foram selecionados 7 estudos caso-controles sobre o impacto do tratamento periodontal nos níveis da CRP. Os estudos são bastante heterogêneos em relação aos parâmetros avaliados, mas observa-se uma melhor padronização metodológica nos estudos mais recentes. Com exceção de dois estudos que não mostraram influência do tratamento periodontal nos níveis da CRP, os outros cinco estudos selecionados demostraram um efeito positivo do tratamento periodontal nos níveis séricos de CRP. Conclusão: Os resultados dos estudos selecionados sugerem uma influência do tratamento periodontal não-cirúrgico nos níveis plasmáticos da proteína C-reativa em pacientes com PC. Apesar de entusiasmantes, até o momento, esses resultados não podem ser extrapolados. Estudos longitudinais bem controlados, com amostras representativas e com parâmetros de avaliação semelhantes são necessários para que conclusões sejam determinadas.
\end{abstract}

Palavras-chave: Periodontite crônica. Proteína C-reativa. Periodontite /Tratamento.

\begin{abstract}
Introduction: Since it was demonstrated that periodontitis can increase C-reactive protein (CRP) levels, studies have sought to demonstrate the impact of periodontal treatment in the CRP levels, but with inconsistent results. Objective: was to evaluate the impact of periodontal treatment in CRP levels in subjects with chronic periodontitis. Searches were conducted in national and international databases until February 2014. The parameters evaluated were: periodontal parameters (probing pocket depth, attachment level, plaque index and bleeding on probing, number of sites per tooth); time of re-evaluation after periodontal treatment, exclusion criteria and prescription of antibiotics. Results: Seven case-control studies were selected. The studies were very heterogeneous in regard to the assessed parameters, but there has been an standardization of the evaluated parameters in more recent studies. Except for two studies that showed no influence of periodontal treatment on the levels of CRP, five studies have shown a positive effect of periodontal treatment on plasma levels of CRP. Conclusion: The results of the selected studies suggest a influence of non-surgical periodontal treatment on plasma levels of C-reactive protein in patients with chronic periodontitis. Although enthusiastic, these results cannot be extrapolated. Well-controlled longitudinal studies with representative samples and with similar parameters are necessary for a definitive conclusion to be drawn.
\end{abstract}

Keywords: Chronic Periodontitis. C-Reactive Protein. Periodontal/Treatment.

\section{INTRODUÇÃO}

As doenças periodontais são geralmente de natureza crônica e resultam da exposição do periodonto a biofilmes acumulados nos dentes. A destruição periodontal resulta, provavelmente, da ação de lipopolissacarídeos, ácidos lipoteicóicos e proteases liberados por bactérias patogênicas do biofilme subgengival, assim como das respostas do hospedeiro contra as bactérias do biofilme e seus

Correspondência / Correspondence: *José Alberto da Silva Franceschine, Faculdade de odontologia da Universidade Veiga de Almeida. Rua Ibituruna, 108, CASA 3, Tijuca. Rio de Janeiro - RJ. CEP 20271-020 subprodutos (VAN DYKE et al., 2009). As duas principais doenças periodontais são a gengivite e a periodontite. $A$ gengivite é um processo inflamatório reversível da gengiva, pois não há destruição dos tecidos de suporte dos dentes. A periodontite é uma condição crônico-inflamatória na qual ocorre destruição do ligamento periodontal, do osso alveolar e, em casos extremos, pode ocorrer a perda dos dentes.

A periodontite é classificada em periodontite agressiva e em periodontite crônica, sendo essa última o tipo mais prevalente (FLEMMIG, 1999). A gengivite acomete de 30 a $50 \%$ da população adulta, enquanto a PC, possui 
uma prevalência de $30 \%$ em indivíduos com mais de 50 anos (LOOS, 2005; BLAKE et al., 2003). Sabe-se que a PC severa acomete em média de 10 a $15 \%$ da população mundial, através de vários estudos seccionais realizados em grupos de diversos locais (BROWN; LOE, 1993). Os resultados da Pesquisa Nacional de Saúde Bucal (SB Brasil 2010) demonstraram que o Índice de Perda de Inserção Periodontal de $4-12 \mathrm{~mm}$ na faixa etária entre 35 e 44 anos foi de $18,3 \%$ e na faixa etária entre 65 e 74 anos foi de $3,9 \%$. Os dados da população adulta entre 45 e 64 não foram divulgados nessa Pesquisa Nacional de Saúde Bucal.

Apesar de a agressão bacteriana ser necessária para a ocorrência da periodontite, o papel central na patogênese da doença é exercido pela resposta do hospedeiro através do controle das respostas imune inata e adaptativa (KINANE; BARTOLD, 2007). Mesmo a periodontite sendo uma infecção crônica, elementos de fase aguda estão envolvidos na resposta imunológica, confirmando que uma inflamação sistêmica está presente (RIDKER et al., 1998). Estes reagentes de fase aguda com propriedades pró-inflamatórias ajudam a neutralizar os patógenos invasivos e estimulam a regeneração dos tecidos e, o mais estudado é a proteína C-reativa (BLAKE et al., 2003; RIDKER et al., 2004).

A proteína $\mathrm{C}$ reativa (CRP) é um biomarcador inflamatório que é produzida nos hepatócitos em resposta de fase aguda do organismo frente a alguma inflamação ou infecção. Diante de um processo inflamatório os níveis da CRP aumentam, chegando a um pico de 1000 vezes o valor normal entre 24 e 72 horas e apresentando meia vida plasmática curta de, aproximadamente, 19 horas (ABBAS, 2011; BLACK, 2004). A secreção da CRP é regulada por citocinas, principalmente a IL-6. A função da CRP é ligar-se a patógenos e células lesadas e/ou apoptóticas e iniciar sua eliminação por meio da ativação do sistema complemento e de fagócitos. É considerada um importante marcador de inflamação sistêmica. Acredita-se que através da mensuração da CRP pode-se monitorar a resposta ao tratamento de certos processos inflamatórios e infecciosos. (RIDKER et al., 1998).

Estudos epidemiológicos têm investigado e apoiado uma associação entre altos níveis de marcadores inflamatórios e o aumento do risco e progressão de doenças cardiovasculares (PACKARD; LIBBY, 2008). Elevadas concentrações da CRP têm sido associadas a risco futuro de eventos cardiovasculares em homens aparentemente saudáveis e podem detectar doenças ocultas no organismo (ZEBRACK et al., 2002; JIALAL; DEVARAJ, 2001). Em indivíduos saudáveis, os níveis de CRP são encontrados em baixos níveis com valores $<0,3 \mathrm{mg} / \mathrm{L}$ (YUDKIN et al., 1999). Os níveis abaixo de $1,0 \mathrm{mg} / \mathrm{L}$ indicam baixo risco para doença cardiovascular. Níveis entre 1,0 e $3,0 \mathrm{mg} /$ $\mathrm{L}$ e superiores a 3,0 $\mathrm{mg} / \mathrm{L}$ indicam médio e alto risco, respectivamente (PEARSON et al., 2003).

Uma meta-análise publicada em 2008 confirmou que níveis elevados de CRP são encontrados em pacientes com periodontite (PARASKEVAS et al., 2008), no entanto, poucos são os estudos que avaliam o impacto do tratamento periodontal não cirúrgico nos níveis da CRP em pacientes com PC sem nenhuma outra doença sistêmica. Sendo assim, o objetivo dessa revisão foi avaliar os estudos sobre o impacto do tratamento periodontal nos níveis da proteína C-reativa em com periodontite crônica sem nenhuma outra doença sistêmica.

\section{METODOLOGIA}

Foram realizadas buscas por artigos publicados sobre o tema até fevereiro de 2014 nas bases de dados PubMed/ MEDLINE e LILACS-BIREME. Foram utilizadas palavras-chave tanto em inglês quanto português já que artigos na língua portuguesa seriam considerados, caso se enquadrasse, nos critérios de inclusão. Dois examinadores (JAF e FB) realizaram a busca e a seleção dos artigos e os três autores (JAF e FB, CMF) realizaram a análise dos artigos. Os estudos selecionados foram realizados em populações adultas. Todos os estudos eram estudos caso-controle.

Os estudos selecionados pertenciam à revistas cujo maior webqualis era $\mathrm{A} 1$ e menor webqualis era $\mathrm{B} 2 \mathrm{e}$, o fator de impacto das revistas em que os estudos foram publicados variavam de 0 a 3.6. (J Clin Periodontology: Impact factor: 3.6 e webqualis A1; J Periodontol: Impact factor: 2.5 e webqualis A1; J Periodontal Research: Impact factor: 2.2 e webqualis A2; Arch Oral Biol: Impact factor: 1.8 e webqualis A2; I Contemp Dent Pract: Impact Factor: 0 e webqualis $B 2$ ).

As palavras-chave utilizadas foram: (1) periodontite crônica, proteína C-reativa e tratamento periodontal, (2) periodontite, proteína C-reativa e tratamento periodontal, (3) doença periodontal, proteína C-reativa e tratamento periodontal e (4) gengivite, proteína C-reativa e tratamento periodontal sendo encontrados 160 artigos. Foram excluídos todos os artigos cujos participantes apresentam doenças crônico-inflamatórias. Oito artigos foram selecionados, mas como um deles não apresentava a média dos níveis séricos proteína C-reativa inicial nem final, apenas a frequência de indivíduos com valores da proteína C-reativa abaixo ou acima do valor de referência, apenas 7 estudos foram incluídos nessa revisão. Nenhum artigo na língua portuguesa foi incluído.

Avaliamos em cada artigo o número de indivíduos do grupo teste (com PC) e o número de indivíduos controles, os parâmetros periodontais avaliados, os critérios de exclusão, o tempo de reavaliação periodontal e nova mensuração da CRP, a utilização de antibióticos sistêmicos como adjuntos ao tratamento periodontal e os principais resultados e conclusões.

A fim de facilitar a comparação dos dados, convertermos todas as medidas da CRP para $\mathrm{mg} / \mathrm{dL}$ e categorizamos as médias inicial e final da CRP em cada estudo de acordo com a avaliação de risco de doença cardiovascular: (1) alto risco: superior a $0,30 \mathrm{mg} / \mathrm{dL}$, médio risco: entre $0,1-0,3 \mathrm{mg} / \mathrm{dL}$ e baixo: $<0,1 \mathrm{mg} / \mathrm{dL}$ (Pearson et al., 2003). 


\section{RESULTADOS}

Os estudos de Patil e Desai 2013, Shimada et al.(2010) e Yamazaki et al. (2005) demostraram que os valores iniciais da CRP no grupo teste correspondiam a um baixo risco de doença cardiovascular. Os estudos de Marcaccini et al. (2009) e Ide et al. (2003) demonstraram que os valores iniciais da CRP no grupo teste correspondiam a um médio risco de doença cardiovascular. Os estudos que demonstraram valores iniciais da CRP no grupo teste que correspondiam a um alto risco de doença cardiovascular foram o de Miyashita et al. (2012) e Kamil et al. (2011).

Após o tratamento periodontal, mesmo havendo uma redução estatisticamente significativa dos valores da PCR, não houve alteração na categoria de risco de doença cardiovascular no estudo de Kamil et al. (2011), os indivíduos permaneceram com um alto risco de doença cardiovascular. O único estudo que demostrou uma mudança no risco de doença cardiovascular foi o de Marcaccini et al. (2009), no qual os indivíduos antes do tratamento periodontal estavam incluídos na categoria de médio risco e após o tratamento periodontal passaram a apresentar baixo risco de doença cardiovascular. Os resultados do estudo de Ide et al. (2003) demonstraram que o tratamento periodontal não influenciou o risco (médio risco).

As informações relevantes dos artigos selecionados estão demonstradas no quadro a seguir:

\begin{tabular}{|c|c|c|c|c|c|c|c|c|c|}
\hline Autor & $\begin{array}{l}\text { Grupo } \\
\text { Teste }\end{array}$ & $\begin{array}{l}\text { Grupo } \\
\text { Controle }\end{array}$ & $\begin{array}{l}\text { Parâmetros } \\
\text { Periodontais }\end{array}$ & $\begin{array}{l}\text { Tempo de } \\
\text { Reavalia- } \\
\text { ção }\end{array}$ & Antibiótico & Fatores exclusão & $\begin{array}{l}\text { Média CRP } \\
\text { inicial }\end{array}$ & $\begin{array}{l}\text { Média CRP } \\
\text { final }\end{array}$ & $\begin{array}{l}\text { Conclusão e resul- } \\
\text { tados }\end{array}$ \\
\hline $\begin{array}{l}\text { 1. Patil e } \\
\text { Desai } 2013\end{array}$ & $\begin{array}{l}20 \text { com PC } \\
\text { leve, } 20 \\
\text { com gengi- } \\
\text { vite }\end{array}$ & $\begin{array}{l}20 \text { perio- } \\
\text { dontalmen- } \\
\text { te saudá- } \\
\text { veis }\end{array}$ & \begin{tabular}{|l|} 
PS e NI (não \\
informou em \\
quantos sítios por \\
dente) \\
Definição de PC: \\
PS 4-5mm e PI \\
3-4mm \\
\end{tabular} & $\begin{array}{l}3 \text { meses } \\
\text { após o TP }\end{array}$ & $\begin{array}{l}\text { Não } \\
\text { informado }\end{array}$ & $\begin{array}{l}\text { sem TP há } 6 \text { meses, } \\
\text { AB e Al } 6 \text { meses } \\
\text { antes, uso de me- } \\
\text { dicação controlada, } \\
\text { DM, fumantes, } \\
\text { cond. Inflamatórias } \\
\text { sistêmicas }\end{array}$ & \begin{tabular}{|l|}
$0.00024 \pm$ \\
0.000047 \\
$\mathrm{mg} / \mathrm{dL}$ (peri- \\
odontite) \\
$0.00014 \pm$ \\
0.000032 \\
$\mathrm{mg} / \mathrm{dL}$ \\
(gengivite) \\
0.000056 \\
\pm 0.00002 \\
$\mathrm{mg} / \mathrm{dL}$ \\
(saudáveis)
\end{tabular} & $\begin{array}{l}0.00013 \pm \\
0.000036 \\
\mathrm{mg} / \mathrm{dL} \\
\text { (periodonti- } \\
\text {-te) } \\
0.000044 \pm \\
0.000023 \\
\mathrm{mg} / \mathrm{dL} \\
\text { (gengivite) }\end{array}$ & $\begin{array}{l}\text { Risco Cardiovascular } \\
\text { Inicial: } \\
\text { Baixo } \\
\text { Risco Cardiovascular } \\
\text { Final: } \\
\text { Baixo }\end{array}$ \\
\hline $\begin{array}{l}\text { 2. Miyashi- } \\
\text { ta et al., } \\
2012\end{array}$ & \begin{tabular}{|l|}
49 \\
PC mo- \\
derada a \\
avançada \\
(PB $\geq 4 \mathrm{~mm})$
\end{tabular} & $\begin{array}{l}40 \\
\text { periodon- } \\
\text { talmente } \\
\text { saudáveis }\end{array}$ & \begin{tabular}{|l|} 
PS, NI (6 sítios), \\
Índice de Pla- \\
ca, RX \\
Definição de PC: \\
não informada
\end{tabular} & $\begin{array}{l}\text { 3-4 meses } \\
\text { após o TP } \\
\text { (não-cirúr- } \\
\text { gico e/ou } \\
\text { cirúrgico) }\end{array}$ & $\begin{array}{l}\text { Cefalospo- } \\
\text { rina por } 4 \\
\text { dias após } \\
\text { a cirurgia } \\
\text { periodontal }\end{array}$ & $\begin{array}{l}\text { Fumantes e ex- } \\
\text {-fumantes. }\end{array}$ & $\begin{array}{l}0.53 \mathrm{mg} / \mathrm{dL} \\
\text { (grupo teste) } \\
0.19 \mathrm{mg} / \mathrm{dL}\end{array}$ & $0.37 \mathrm{mg} / \mathrm{dL}$ & $\begin{array}{l}\text { Risco Cardiovascular } \\
\text { Inicial: } \\
\text { Alto } \\
\text { Risco Cardiovascular } \\
\text { Final: } \\
\text { Alto } \\
\text { Níveis de CRP são } \\
\text { independentes dos } \\
\text { títulos de AC p/ } \\
\text { Porphyromonas gin- } \\
\text { givalis. No entanto, } \\
\text { níveis de CRP foram } \\
\text { + altos nos ind. com } \\
\text { periodontite crônica }\end{array}$ \\
\hline $\begin{array}{l}\text { 3.Kamil et } \\
\text { al., } 2011\end{array}$ & $\begin{array}{l}18 \text { com PC } \\
\text { avançada }\end{array}$ & $\begin{array}{l}18 \text { com PC } \\
\text { avançada. } \\
\text { (IHO, após } \\
\text { a conclusão } \\
\text { do estudo } \\
\text { foram } \\
\text { submetidos } \\
\text { ao TP) }\end{array}$ & \begin{tabular}{|l|} 
PS e NI (6 sítios), \\
índice de placa e \\
índice gengival (4 \\
sítos) \\
Definição de PC \\
avançada: PS > \\
$5 \mathrm{~mm}$ e PI $\geq 3 \mathrm{~mm}$ \\
em 3 sítios dos \\
dentes envol- \\
vidos.
\end{tabular} & $\begin{array}{l}3 \text { meses } \\
\text { após o TP }\end{array}$ & Não & $\begin{array}{l}\text { Ao menos } 20 \\
\text { dentes, sem TP } \\
\text { há } 6 \text { meses, } A B 3 \\
\text { meses antes, uso } \\
\text { de medicação } \\
\text { controlada, DM, } \\
\text { Grávida, fumante } \\
<12 \text { meses ou } \\
\text { sofrendo cond. } \\
\text { Inflamatória } \\
\text { sistêmica }\end{array}$ & \begin{tabular}{|l}
$2.3 \pm 0.7$ \\
$\mathrm{mg} / \mathrm{dL}$ \\
$2.3 \pm 0.7$ \\
$\mathrm{mg} / \mathrm{dL}$ \\
(grupo \\
controle)
\end{tabular} & $\begin{array}{l}1.8 \pm 0.6 \\
\mathrm{mg} / \mathrm{dL}\end{array}$ & $\begin{array}{l}\text { Risco Cardiovascular } \\
\text { Inicial: } \\
\text { Alto } \\
\text { Risco Cardiovascular } \\
\text { Final: } \\
\text { Alto } \\
\text { Redução significativa } \\
\text { no grupo teste }\end{array}$ \\
\hline $\begin{array}{l}\text { 4. Shimada } \\
\text { et al., } 2010\end{array}$ & \begin{tabular}{|l}
33 com \\
PC -22 \\
fumantes \\
e 11 não \\
fumantes
\end{tabular} & $\begin{array}{l}18 \\
\text { periodon- } \\
\text { talmente } \\
\text { saudáveis }\end{array}$ & $\begin{array}{l}\text { PS, NI, SS, IP, IG, } \\
\text { (6 sítios), Rx } \\
\text { Definição de PC: } \\
\text { de acordo com a } \\
\text { classificação pro- } \\
\text { posta pela AAP, } \\
\text { sem especificar } \\
\text { valores. }\end{array}$ & $\begin{array}{l}1 \text { mês após } \\
\text { o TP }\end{array}$ & Não & \begin{tabular}{|l|} 
Menos que 20 \\
dentes \\
Gravidez, doenças \\
sistêmicas rele- \\
vantes, sem TP em \\
3 anos
\end{tabular} & \begin{tabular}{|l}
$0.080 \pm$ \\
0.010 \\
$\mathrm{mg} / \mathrm{dL}$ \\
(teste) \\
$0.022 \pm$ \\
0.023 \\
$\mathrm{mg} / \mathrm{dL}$ \\
(controle)
\end{tabular} & $\begin{array}{l}0.049 \pm \\
0.047 \\
\mathrm{mg} / \mathrm{dL}\end{array}$ & $\begin{array}{l}\text { Risco Cardiovascular } \\
\text { Inicial:Baixo } \\
\text { Risco Cardiovascular } \\
\text { Final:Baixo } \\
\text { O TP foi efetivo em } \\
\downarrow \text { CRP. } \\
\mathrm{P}=0.048 \text {. Resultado } \\
\text { significante. }\end{array}$ \\
\hline
\end{tabular}


Impacto do tratamento periodontal não-cirúrgico nos níveis plasmáticos da proteína c-Reativa em pacientes com periodontite crônica: revisão da literatura

\begin{tabular}{|c|c|c|c|c|c|c|c|c|c|}
\hline Autor & $\begin{array}{l}\text { Grupo } \\
\text { Teste }\end{array}$ & $\begin{array}{l}\text { Grupo } \\
\text { Controle }\end{array}$ & $\begin{array}{l}\text { Parâmetros } \\
\text { Periodontais }\end{array}$ & $\begin{array}{l}\text { Tempo de } \\
\text { Reavalia- } \\
\text { ção }\end{array}$ & Antibiótico & Fatores exclusão & $\begin{array}{l}\text { Média CRP } \\
\text { inicial }\end{array}$ & $\begin{array}{l}\text { Média CRP } \\
\text { final }\end{array}$ & $\begin{array}{c}\text { Conclusão e resul- } \\
\text { tados }\end{array}$ \\
\hline $\begin{array}{l}\text { 5. Marcac- } \\
\text { cini et al., } \\
2009\end{array}$ & $25 \mathrm{com}$ PC & $\begin{array}{l}20 \text { perio- } \\
\text { dontalmen- } \\
\text { te saudá- } \\
\text { veis }\end{array}$ & $\begin{array}{l}\text { PS e PI (6 sítios) } \\
\text { Definição de PC: } \\
\text { pelo menos } 2 \\
\text { dentes com PS } \geq \\
5 \mathrm{~mm}, \mathrm{PI} \geq 6 \mathrm{~mm} \text { e } \\
\text { evidência radi- } \\
\text { gráfica de perda } \\
\text { óssea alveolar. }\end{array}$ & $\begin{array}{l}3 \text { meses } \\
\text { após o TP }\end{array}$ & Não & $\begin{array}{l}\text { Menos } 20 \text { dentes, } \\
\text { lesão periapical } \\
\text { não tratada, / TP } \\
\text { há } 6 \text { meses, AB nos } \\
\text { últimos } 6 \text { meses, } \\
\text { fazendo uso de } \\
\text { medicamentos } \\
\text { que interferem na } \\
\text { resposta inflama- } \\
\text { tória nos últimos } \\
6 \text { meses, DM, } \\
\text { Grávidas, lactantes, } \\
\text { fumante, ex-fuman- } \\
\text { te há menos de } \\
10 \text { anos, doenças } \\
\text { Inflamatórias ou } \\
\text { imunológicas }\end{array}$ & $\begin{array}{l}0.12 \mathrm{mg} / \mathrm{dL} \\
\text { (teste) } \\
\mathrm{e} \\
0.09 \mathrm{mg} / \mathrm{dL} \\
\text { (controle) }\end{array}$ & $\begin{array}{l}\text { Aproximada- } \\
\text { mente } \\
0.06 \mathrm{mg} / \mathrm{dL}\end{array}$ & $\begin{array}{l}\text { Risco Cardiovascular } \\
\text { Inicial: } \\
\text { Médio } \\
\text { Risco Cardiovascular } \\
\text { Final: } \\
\text { Baixo } \\
\text { Redução significativa } \\
\text { no grupo teste }\end{array}$ \\
\hline $\begin{array}{l}\text { 6. Yamazaki } \\
\text { et al., } 2005\end{array}$ & $\begin{array}{l}24 \text { com PC } \\
\text { moderada a } \\
\text { avançada }\end{array}$ & $\begin{array}{l}21 \\
\text { periodon- } \\
\text { talmente } \\
\text { saudáveis }\end{array}$ & $\begin{array}{l}\text { PS, NI (6 sítios), } \\
\text { Índice de Pla- } \\
\text { ca, RX } \\
\text { Definição de PC: } \\
\text { não informada }\end{array}$ & $\begin{array}{l}3 \text { meses } \\
\text { após o TP } \\
\text { (não-cirúr- } \\
\text { gico e/ou } \\
\text { cirúrgico) }\end{array}$ & $\begin{array}{l}\text { AB por } 4 \\
\text { dias após } \\
\text { a cirurgia } \\
\text { periodontal }\end{array}$ & $\begin{array}{l}\text { Fumantes, } \\
\text { TP prévio e } \\
\text { AB até } 3 \text { meses }\end{array}$ & $\begin{array}{l}0.031 \mathrm{mg} / \mathrm{dL} \\
0.019 \mathrm{mg} / \mathrm{dL}\end{array}$ & $0.026 \mathrm{mg} / \mathrm{dL}$ & $\begin{array}{l}\text { Risco Cardiovascular } \\
\text { Inicial: } \\
\text { Baixo } \\
\text { Risco Cardiovascular } \\
\text { Final: } \\
\text { Baixo } \\
\text { Níveis de CRP com } \\
\text { uma tendência a } \\
\text { diminuir após o } \\
\text { tratamento. } \\
\text { Não houve diferença } \\
\text { significativa entre } \\
\text { controles e teste } \\
\text { antes do tratamento } \\
\text { e nem após o TP. }\end{array}$ \\
\hline $\begin{array}{l}\text { 7. Ide et al., } \\
2003\end{array}$ & $\begin{array}{l}24 \text { com PC } \\
\text { moderada a } \\
\text { severa } \\
\text { TP ime- } \\
\text { diato } \\
\text { ( } 30 \text { a } 60 \\
\text { anos) }\end{array}$ & $\begin{array}{l}15 \text { com PC } \\
\text { moderada a } \\
\text { severa } \\
\text { TP } 3 \text { meses } \\
\text { depois }\end{array}$ & $\begin{array}{l}\text { PS, SS, IP, RX, (4 } \\
\text { sítios) } \\
\text { Definição de PC: } \\
\text { pelo menos } 5 \\
\text { dentes com sítios } \\
\text { com PS } \geq 5 \mathrm{~mm} \text { e } \\
\text { evidência radi- } \\
\text { gráfica de perda } \\
\text { óssea alveolar. }\end{array}$ & $\begin{array}{l}6 \text { semanas } \\
\text { após o TP }\end{array}$ & Não & $\begin{array}{l}\text { menos } 20 \text { dentes, } \\
\text { lesão periapical } \\
\text { não tratada, / TP } 6 \\
\text { meses, AB, Al nos } \\
\text { últimos } 6 \text { meses, } \\
\text { DM, Grávidas, } \\
\text { lactantes, fumante, } \\
\text { ex-fumante há } \\
\text { menos de 5anos, } \\
\text { doença Inflamató- } \\
\text { ria ou imunológica }\end{array}$ & $\begin{array}{l}0.14(0.063- \\
0.25) \mathrm{mg} / \mathrm{dL} \\
\text { grupo } 1 \\
0.21(0.026- \\
0.29) \mathrm{mg} / \mathrm{dL} \\
\text { grupo } 2\end{array}$ & $\begin{array}{l}0.12(0.039- \\
0.24) \mathrm{mg} / \mathrm{dL} \\
- \text { grupo } 1 \\
0.19(0.053- \\
0.29) \mathrm{mg} / \mathrm{dL} \\
\text { grupo } 2\end{array}$ & $\begin{array}{l}\text { Risco Cardiovascular } \\
\text { Inicial: } \\
\text { Médio } \\
\text { Risco Cardiovascular } \\
\text { Final: } \\
\text { Médio } \\
\text { TP não influenciou } \\
\text { níveis de marcado- } \\
\text { res inflamatórios } \\
\text { (incluindo CRP) }\end{array}$ \\
\hline
\end{tabular}

Quadro 1 - Impacto do tratamento periodontal nos níveis da CRP em indivíduos sistemicamente saudáveis

PS- Profundidade de sondagem; PI - Perda de inserção; NI - Nível de Inserção; SS - sangramento a sondagem; IG - índice gengival; IP índice de placa; $\mathrm{RX}$ - raios-X; IHO - instrução de higiene oral; $\mathrm{AB}$ - antibiótico; AI - antiinflamatório; DM - diabetes mellitus; TP - tratamento periodontal; PC - periodontite crônica. AAP: Academia Americana de Periodontia. Avaliação de risco de doença cardiovascular: (1) risco alto: superior a $0,30 \mathrm{mg} / \mathrm{dL}$, risco médio: entre $0,1-0,3 \mathrm{mg} / \mathrm{dL}$ e risco baixo: $<0,1 \mathrm{mg} / \mathrm{dL}$.

\section{DISCUSSÃO}

Essa revisão de literatura demonstrou que ainda são poucos os estudos que investigam o efeito da terapia periodontal nos níveis de CRP em pacientes com PC sem outra alteração sistêmica. No entanto, esses estudos demonstram um efeito do tratamento periodontal sobre os níveis da CRP, sugerindo que a infecção periodontal pode ser uma condição crônica não diagnosticada que contribui para a inflamação sistêmica.

Além de serem poucos os estudos realizados sobre o assunto, os parâmetros avaliados são bastante heterogêneos o que não permite a realização de uma metanálise. Os estudos apresentam variações em relação ao grupo controle, ao exame periodontal, à definição da doença periodontal e ao tempo de reavaliação. Enquanto alguns estudos constituem seus grupos controles com indivíduos também com PC e que não são submetidos ao tratamento periodontal no mesmo momento do grupo teste (KAMIL et al., 2011; IDE et al., 2003), outros estudos apresentam grupo controles periodontalmente saudáveis (DESAI, 2013; MARCACCINI et al., 2009; MIYASHITA et al., 2012; PATIL; SHIMADA et al., 2010, YAMAZAKI et al., 2005). A utilização de antibióticos associada ao tratamento periodontal foi encontrada em apenas 1 estudo (MIYASHITA et al., 2012). O ideal é que possamos observar o efeito do tratamento periodontal não-cirúrgico sem a associação de agentes antimicrobianos sistêmicos a fim de termos uma dimensão do impacto da intervenção local na resposta sistêmica.

Em apenas dois dos sete estudos selecionados (IDE et al., 2003; KAMIL et al., 2011), o exame periodontal foi 
realizado em 4 sítios. Com exceção do estudo de Patil e Desai (2013) que não informaram o número de sítios examinados, todos os outros estudos incluídos nessa revisão avaliaram os parâmetros PS e PI em 6 sítios por dente, que é o padrão-ouro. Os parâmetros periodontais PS e PI foram avaliados em todos os estudos, com exceção do estudo de Kamil et al. (2011) que avaliou somente a PS e não avaliou a PI. Patil e Desai (2013) apresentaram um subgrupo com gengivite e demonstraram que os níveis séricos da CRP estavam elevados e que houve uma diminuição após o tratamento periodontal. Parece interessante que estudos futuros também incluam pacientes com gengivite para que os dados possam ser comparados.

Há uma variação no tempo de reavaliação dos níveis plasmáticos da CRP após a intervenção periodontal. Enquanto a maioria dos estudos faz a reavaliação após 3 meses do tratamento periodontal ter sido concluído, Shimada et al. (2010) fizeram a reavaliação 1 mês após o tratamento periodontal e demonstraram um resultado estatisticamente significativo. É provável que a homeostasia seja atingida após determinado tempo e que um período de 3 meses seja adequado para a reavaliação dos níveis plasmáticos da CRP. Kamil et al. (2011), após o tratamento periodontal não-cirúrgico, realizaram 2 vezes por mês reforço da instrução de higiene oral e re-rasparam os sítios sangrantes sugerindo que a manutenção de um periodonto saudável, através da redução dos sinais de inflamação periodontal tiveram um impacto positivo na diminuição dos níveis da CRP. Parece interessante que os próximos estudos realizem esse mesmo reforço da instrução de higiene oral e re-raspagem dos sítios sangrantes dos participantes e informem a frequência dessas consultas.

Alguns estudos mostraram-se mais criteriosos com relação aos fatores de exclusão, o que os tornam extremamente interessantes porque excluem vários fatores de confundimento. $O$ ponto negativo é que quanto mais criterioso o estudo, menor é a amostra, o que pode vir a comprometer o poder estatístico do estudo. Com exceção de Shimada 2010 que subdividiu o grupo teste entre fumantes e não fumantes, todos os artigos selecionados excluíram pacientes fumantes. Como o fumo é um importante fator de risco para a periodontite, é interessante que os próximos estudos apresentem os resultados do impacto do tratamento periodontal em fumantes e não fumantes separadamente.

Para que os estudos demonstrem com fidedignidade as características da população estudada, seria interessante que os indivíduos do grupo teste fossem analisados como um grande grupo, mas que também fossem analisados distribuídos nas três categorias de riscos cardiovasculares existentes (alto, médio e baixo risco de doença cardiovascular). É provável que a inclusão de indivíduos no grupo teste que apresentem baixos níveis de CRP interfiram na interpretação final dos resultados do impacto sistêmico do tratamento periodontal. É improvável pensar no impacto do tratamento periodontal nos níveis de CRP, se esses níveis já eram baixos antes mesmo do início do tratamento periodontal.

Entre os artigos selecionados nessa revisão, em 4 estudos a média da CRP inicial indicava baixo risco de doença cardiovascular, o que não significa que todos os indivíduos estivessem nessa categoria de risco. Baseado nesses estudos, não sabemos quantos eram os indivíduos nas categorias de médio e alto risco de doença cardiovascular e tampouco como foi a resposta ao tratamento periodontal dos indivíduos com médio e alto risco de doença cardiovascular. Um desenho de estudo adequado para determinar o impacto do tratamento periodontal nos níveis da CRP deverá comtemplar uma distribuição similar das três categorias de risco cardiovascular no grupo teste, sempre respeitando o poder estatístico do estudo. Dessa forma, os indivíduos com baixos níveis de CRP não serão excluídos dos estudos, mas poderemos observar separadamente o impacto do tratamento periodontal nos indivíduos do grupo teste de modo que o estudo reflita a população estudada e os resultados sejam consistentes e reproduzíveis.

\section{CONCLUSÃO}

Não existem atualmente estudos de intervenção em larga escala e com resultados consistentes que investigam o efeito da terapia periodontal nos níveis de CRP em pacientes com PC sem outra alteração sistêmica. A associação baseada em evidências entre a doença periodontal severa e a elevação dos níveis séricos de CRP, pode ser utilizada para enfatizar a necessidade de uma ótima saúde oral na população em geral. A avaliação de doença periodontal e seu tratamento devem ser instituídos com mais ênfase em programas de saúde no intuito de melhorar o estado geral de saúde dos indivíduos.

É necessário que estudos baseados em amostras representativas, através de acompanhamentos longitudinais bem controlados e com metodologias semelhantes sejam realizados para determinar o efeito da terapia periodontal na concentração sérica de CRP em indivíduos PC sem nenhuma outra doença sistêmica.

Os resultados dos estudos selecionados sugerem uma influência do tratamento periodontal não-cirúrgico nos níveis plasmáticos da proteína C-reativa em pacientes com PC. Apesar de entusiasmantes, até o momento, esses resultados não podem ser extrapolados.

\section{REFERÊNCIAS}

1. ABBAS, A. K.; LITCHMAN, A.; PILLAI, S. Imunologia celular e molecular. 7. ed. In: LITCHMAN, A. Imunidade Inata. Rio de Janeiro: Elsevier, 2011. cap. 4, p. 55-88.

2. BLAKE, G. J. et al. Blood pressure, C-reactive protein, and risk of future cardiovascular events. Circulation AHA Journals Inicio, Dallas, n.108, p. 2993-2999, 2003.

3. BLACK, S.; KUSHNER, I.; SAMOLS D. C-reactive protein. J. biol. chem., Cleveland, v. 279, n. 47, p. 44487-48490, 2004.

4. BROWN, L. J.; LOE, H. Prevalence, extent, severity and progression of 
periodontal disease. Periodontol 2000, Copenhagen, v. 2, p. 57-71, 1993.

5. FLEMMIG, T. F. Periodontitis. Ann. periodontol, Chicago, v. 4, n. 1, p. $32-38,1999$

6. IDE, M. et al. Effect of treatment of chronic periodontitis on levels of serum markers of Acutephase inflammatory and vascular responses. J.clin. periodontol, Copenhagen, v. 30, p. 334-340, 2003.

7. JIALAL, I.; DEVARAJ, S. The Value of the High-Sensitivity C-Reactive Protein Assay as a Risk Marker. Am. j. clin. pathol., Baltimore, v. 116, n.1, p.108-115, 2001.

8. KAMIL, W. et al. Effects of nonsurgical periodontal therapy on C-reactive protein and serum lipids in Jordanian adults with advanced periodontitis. J. periodontal. res., Copenhagen, v. 46, n. 5, p. 616-621, 2011.

9. KINANE, D.; BARTOLD, P. Clinical relevance of the host responses of periodontitis. Periodontol. 2000., Copenhagen, v. 43, p. 278-293, 2007.

10. LOOS, B. G. Systemic markers of inflammation in periodontitis. J. periodontal., Chicago, v. 76, p. 2106-2115. 2005.

11. MIYASHITA, H. et al. Relationship between serum antibody titres to Porphyromonas gingivalis and hs-CRP levels as inflammatory markers of periodontitis. Arch. oral. biol., Oxford, v. 57, n.6, p. 820-829, 2012.

12. MARCACCINI, A.M. et al. Circulating interleukin- 6 and high-sensitivity C-reactive protein decrease after periodontal therapy in otherwise healthy subjects. J. periodontol., Chicago, v. 80, n.4, p. 594-602, 2009.

13. MINISTÉRIO DA SAÚDE. Secretaria de Atenção à Saúde. Secretaria de Vigilância em Saúde. SB Brasil 2010: Pesquisa Nacional de Saúde Bucal: resultados principais. Brasília,DF: Ms, 2012. p. 106.

14. PACKARD, R.R.S., LIBBY, P. Inflammation in atherosclerosis: from vascular biology to biomarker discovery and risk prediction. Clin. chem., Boston, v. 54, n. 1, p. 24-38, 2008

15. PARASKEVAS, S. et al. A systematic review and meta-analyses on C-reactive protein in relation to periodontitis. J. clin. periodontol., Copenhagen, v. 35, n. 4, p. 277-290, 2008.
16. PATIL, V.A.; DESAI, M. H. Effect of periodontal therapy on serum C-reactive protein levels in patients with gingivitis and chronic periodontitis: a clinic biochemical study. The Journal of contemporary Dental Practice, New Delhi, v. 14, n. 2, p. 233-237, 2013.

17. PEARSON, T. et al. Centers for Disease Control and Prevention; American Heart Association. Markers of inflammation and cardiovascular disease: application to clinical and public health practice: A statement for healthcare professionals from the Centers for Disease Control and Prevention and the American Heart Association, Circulation, Dallas, v. 107, n. 3, p. 499-511, 2003.

18. RIDKER, P. M.; HAUGHIE, P. Prospective studies of C-reactive protein as a risk factor for cardiovascular disease. J. Investig Med, Philadelphia, v. 46, n. 8, p. 391-395, 1998.

19. RIDKER, P. M. et al. Established and emerging plasma biomarkers in the prediction of first atherothrombotic events. Circulation, Dallas, v. 109, Supl.25, p. 6-19, 2004.

20. SHIMADA, Y. et al. The effect of periodontal treatment on serum leptin, interleukin-6, and C-reactive protein. J. periodontal., Chicago, v. 81,n. 8, p. 1118-1123, 2010.

21. VAN DYKE, T. E. Resolution of inflammation unraveling mechanistic links between periodontitis and cardiovascular disease. J. dentistry, Bristol, v. 37, n. 8, p. 582-583, 2009

22. YAMAZAKI, K. et al. Effect of periodontal treatment on the C-reactive protein and proinflammatory cytokine levels in Japanese periodontitis patients. J. periodontal res., Copenhagen, v. 40, n. 1, p. 53-58, 2005.

23. YUDKIN, J. S. et al. C-reactive protein in healthy subjects: associations with obesity, insulin resistance, and endothelial dysfunction: a potencial role for cytokines originating from adipose tissue? Arterioscler Thromb. Vasc. Biol., Dallas, v. 19, n. 4, p. 972-978, 1999.

24. ZEBRACK, J. S. et al. C-reactive protein and angiographic coronary artery disease: independent and additive predictors of risk in subjects with angina. The Intermountain Heart Collaboration Study Group. J. Am. Coll. Cardiol., New York, v. 39, n. 4, p. 632-637, 2002.

Submetido em: 03.10.2014

Aceito em: 21.01.2015 